\title{
AS INFLUÊNCIAS IDEOLÓGICAS DO TRABALHO E AS PERSPECTIVAS PARA O SÉCULO XXI
}

\section{Christian Marcello Mañas}

Especialista em Economia do Trabalho, Mestrando em Direito das

Relações Sociais na UFPR, Advogado.

SUMÁRIO: Introdução: trabalho e ideologia; 1 Pensamento filosófico na antigüidade; 2 Imposição religiosa na idade média; 3 Visão econômica na idade moderna; $4 \mathrm{O}$ trabalho pulverizado; Considerações finais; Referências bibliográficas.

\section{INTRODUÇÃO: TRABALHO E IDEOLOGIA}

O conceito de ideologia fora usado pela primeira vez no século XVIII, por DESTUTT DE TRACY, para caracterizar um estudo das idéias objetivando a investigar cientificamente sua gênese biológica, suas características objetivas e suas repercussões no campo social. Já em uma nova etapa de identificação, fora utilizada na metade do século XIX por KARL MARX, que via na luta de classes o motor da História, sempre destacando a presença dominante do processo ideológico em forma de crenças, interesses subalternos, ou concretizado em instituições opressivas. ${ }^{1}$

Ainda que o termo ideologia tenha aparecido a poucos séculos, nada impede que o mesmo seja aplicado às sociedades antigas e medievais, cujos indivíduos estavam dotados de idéias que determinavam suas atitudes e comportamentos acerca da realidade, ainda que inconscientemente. Naturalmente, o trabalho não poderia ficar alheio a ela.

O trabalho foi exaltado ou desprezado em diferentes épocas e por diversos grupos sociais, cada qual com suas ideologias e formas de sobrepujar os indivíduos. A idéia de que o homem, com o trabalho, adquire um engrandecimento pessoal, elevando-se como ser humano e ser social, modificando o mundo material em que vive, é moderna, face ao entendimento antigo e medieval.

Viabiliza-se a demonstração de um enfoque explicativo da transformação do processo vital humano, inserto no interior da ideologia do trabalho, percorrendo as relações tradicionais do homem com seu tempo, via posições filosóficas, religiosas e econômicas, as quais influenciaram o sistema produtivo moderno e as diversas formas pelas quais o trabalho se manifesta.

\section{PENSAMENTO FILOSÓFICO NA ANTIGÜIDADE}

O mundo antigo nunca tratou o trabalho com prestígio e nobreza. Em verdade, na Grécia, há quase unanimidade em afirmar que o trabalho significava uma atividade

1 Cf. MENDES, Antonio Celso. Direito: ciência, ideologia, política. Curitiba: Livros HDV, 1984, p. 112-113. 
secundária. ${ }^{2}$ Para os gregos, os homens livres deveriam viver no ócio, em atividades que indicavam a contemplação à natureza ou às prerrogativas políticas, abstraindo-se em trabalho intelectual. De outro lado, o trabalho físico era renegado aos escravos e às mulheres, consubstanciando em atividades indignas e humilhantes, necessárias à manutenção das cidades. Esses realizavam atividades agrícolas, em pequenas indústrias, no porto, no trabalho doméstico, além de serviços públicos. ${ }^{3}$

A elite se sustentava pela máxima de ARISTÓTELES "pensar requer ócio", desobrigando-se do trabalho e se utilizando dos escravos por meio de argumentos sutis que justificassem a necessidade da escravidão, a qual era tida como lei natural, livrando os cidadãos das tarefas servis, permitindo "consagrar-se melhor à cidade, aos prazeres do corpo ou à investigação e à contemplação das coisas eternas do espírito". ${ }^{4}$ PLATÃO afirmava que, como os homens eram diferentes por natureza, cabia a cada qual estar no lugar em que melhor expressasse e desenvolvesse suas qualidades, e, dessa forma, ficava justificado o papel reservado ao escravo. ${ }^{5}$

Encarar o trabalho como degradante e, em conseqüência, conceder pouca atenção à invenção técnica foram características das sociedades escravistas.

\section{IMPOSIÇÃO RELIGIOSA NA IDADE MÉDIA}

Após um período conturbado na História, a escravidão passou por uma redução significativa face a diversos fatores, dentre os quais: a forte atuação da Igreja, que enaltecia a vantagem da libertação dos escravos devido às circunstâncias econômicas da época; o custo de manutenção dos escravos nos latifúndios, que se tornou progressivamente superior ao custo da subdivisão dos mesmos em pequenas propriedades entregues aos colonos para o cultivo; o enfraquecimento da autoridade central, tornando cada vez mais difícil a manutenção do controle das massas de "gado humano". ${ }^{\circ}$

Na Idade Média, predominou o regime da servidão, um meio-termo entre a escravidão e o trabalho livre. As classes dominantes, nobreza e clero, evitavam ao

2 Muitos defendem que o descaso dos gregos pelo trabalho não se coloca por ser ele manual, mas sim devido à sua simplificação, por dispensar qualquer qualificação e por suas atividades monótonas e jornadas de longa duração, sem técnica e criatividade. Nesse sentido, cf. CARMO, Paulo Sérgio do. $A$ ideologia do trabalho. 8. ed. São Paulo: Moderna, 1996, p. 18-19.

3 DE MASI afirma que "apenas quatro em cada dez pessoas eram cidadãos de pleno direito, que se dedicavam à política, à filosofia, à ginástica e à poesia, e que, materialmente, viviam à custa dos outros seis a quem eram relegadas todas as atividades de natureza e de serviço. (...) Não ter nenhum escravo era sinal de extrema pobreza." (DE MASI, Domenico. Desenvolvimento sem trabalho. 4. ed. São Paulo: Esfera, 1999, p. 19)

4 CARMO, Paulo Sérgio do. Op. cit., p. 17.

5 PLATÃO, no parágrafo 2480 de Fedro, classifica as profissões em nove categorias dispostas nesta ordem decrescente de reconhecimento social: o filósofo, o bom rei, o político, o esportista, o adivinho, o poeta, o agricultor e o artesão, o demagogo, o tirano. Cf. DE MASI, Domenico. Op. cit., p. 13.

6 Ver DE MASI. Op. cit., p. 22-30. 
máximo o trabalho, embora pregassem a necessidade de que o mesmo imperasse sobre toda a sociedade.

No início do cristianismo, o trabalho era visto como expiação pelo pecado, ${ }^{7}$ servindo também como condição de afastamento dos maus pensamentos gerados pela preguiça e pela ociosidade. Não era visto como atividade nobre ou até mesmo como fonte de prazer. Era exaltado apenas na medida em que contribuía para o disciplinamento das pessoas, tornando-as ocupadas, conduzindo à restauração da pureza da mente e para a resignação cristã. Ou seja, não havia veneração do trabalho em prol de uma possibilidade de aumento da produtividade, tal como se dera em momento histórico posterior, mas sim como ponte para se chegar à salvação e à graça divina. As conseqüências de uma atitude diferente significavam, além da perda do trabalho, a condenação às chamas do inferno. ${ }^{8}$

Com a Reforma Protestante ocorrida no século XVI, o trabalho passou a ser redimensionado dentro do cristianismo, sendo visto como forma de servir a Deus, mantendo distância do ócio e da luxúria. Trabalhar constituiu-se como finalidade de vida, de obtenção de êxito e prosperidade. A Igreja, via protestantismo, propagou uma doutrina do trabalho como meio de atingimento de uma felicidade que, todavia, ficava resguardada para uma vida futura.

Para LUTERO, o trabalho era o caminho para a salvação, aparecendo como a base da vida. Como justificativa, afirmava que todo homem capacitado para laborar tinha o dever de fazê-lo, pois dessa forma estaria servindo a Deus e se afastando do ócio, visto como evasão antinatural e perniciosa. ${ }^{9}$

De outro lado, com diferentes argumentos, CALVINO associava o trabalho à idéia de predestinação, ou seja, era da vontade de Deus que alguns homens trabalhassem e outros não, e era só dessa forma que os mesmos atingiriam o êxito. Assim, de maneira cíclica os homens deveriam ser reinvestidos para permitir e incentivar cada vez mais o trabalho. ${ }^{10}$

Toda essa paulatina mudança ficou evidenciada no estudo de WEBER, ${ }^{11}$ acerca da ética protestante, em que a conduta racional tinha por princípios valores morais que iam ao encontro dos ideais do capitalismo emergente. Havia uma afinidade entre a

7 A própria interpretação da Bíblia, em determinadas passagens, leva à critica ao apego demasiado pelo trabalho, entendendo-o até mesmo como castigo. Como exemplificação, tem-se que, por perderem a inocência original do paraíso, Adão foi condenado a ganhar o seu pão com o suor de seu rosto, assim como Eva foi condenada às dores do parto. Ver ALBORNOZ. O que é trabalho. São Paulo: Brasiliense, 2000 , p. 51.

8 THOMPSON, Edward P. A formação da classe operária inglesa: a maldição de Adão. Rio de Janeiro: Paz e Terra, v. 2, 1987, p. 249.

9 Ver ALBORNOZ. Op. cit., p. 52-54.

10 Idem, p. 52-54.

11 WEBER, Max. A ética protestante e o espírito do capitalismo. 15. ed. São Paulo: Pioneira, 2000. 
idéia protestante de vocação e a compulsividade para o lucro, advinda da ascensão da economia capitalista. ${ }^{12}$

Ainda que por justificativas diversas, tanto o catolicismo quanto o protestantismo postergavam a igualdade para o reino divino futuro, perpetuando, no presente, a injustiça social.

\section{VISÃO ECONÔMICA NA IDADE MODERNA}

Os discursos moralizantes e religiosos acerca do trabalho têm seu espaço ocupado, aos poucos, por teorias que encontravam no trabalho o objeto específico de profundas reflexões econômicas.

Com o crescimento das cidades, o desenvolvimento do trabalho livre e a criação de pequenas fábricas, passou-se a compor uma nova ótica manifestada acerca da necessidade e admiração pelo trabalho e seu valor. A expansão comercial e financeira propiciou o surgimento do capitalismo no século XVIII.

A partir de então, a produção e a produtividade imperaram como base do sistema mercadológico, tornando anti-sistêmicos o ócio e a indolência. O seu desenvolvimento só foi possível devido à mão-de-obra disponível em grande escala. Conforme CARMO expõe: "No início, lançou-se mão do crescente exército de camponeses e artesãos arruinados, oriundos da destruição da sociedade pré-capitalista medieval: expulsos das terras e das aldeias, desenraizados e sem uma situação segura na sociedade, infestavam as estradas, pilhando e matando. É esse melancólico exército de decaídos, mendigos, vagabundos e mercenários que forma os primeiros proletários". ${ }^{13}$

A ideologia liberal baseou-se em um conjunto de idéias contrárias à intervenção do Estado na economia e favorável à livre concorrência dos mercados. Exaltou-se, principalmente, a "liberdade" que os indivíduos tinham para negociar e vender sua força de trabalho. Diante de todo esse quadro, cristalizou-se a forma pela qual a construção da teoria econômica auxiliaria a entender a natureza do trabalho.

O núcleo de tudo isso reside justamente no novo conceito de trabalho que os economistas introduziram, conferindo-lhe uma significação homogênea, mercantil e abstrata.

A contribuição principal no pensamento econômico clássico por excelência, destacando ADAM SMITH e DAVID RICARDO, foi a ruptura com o mercantilismo ao centrarem a origem da riqueza capitalista no trabalho humano.

12 WEBER bem retrata tal situação: "O poder da ascese religiosa, além disso, punha à sua disposição trabalhadores sóbrios, conscientes e incomparavelmente industriosos, que se aferravam ao trabalho como a uma finalidade de vida desejada por Deus. Dava-lhe, além disso, a tranqüilizadora garantia de que a desigual distribuição da riqueza deste mundo era obra especial da Divina Providência, que, com essas diferenças, e com a graça particular, perseguia seus fins secretos, desconhecidos do homem". (Op. cit., p. 127)

13 CARMO, Paulo Sérgio do. Op. cit., p. 28. 
Precursor dos estudos acerca do trabalho, ${ }^{14}$ SMITH constatou que a riqueza dos países não residia apenas no ouro, na prata ou mesmo na agricultura, mas sim no trabalho, ${ }^{15}$ capaz de transformar matéria-prima em produtos com valor de mercado. Para o economista, o conflito central do capitalismo era retratado pela relação entre trabalhadores e capitalistas, ou seja, entre capital e trabalho e que a trabalho corresponde salários, e ao capital, lucro. O antagonismo de classes, não apenas entre trabalhadores e industriais, como também entre estes e os proprietários fundiários, foi radicalizado na teoria do valor de DAVID RICARDO. ${ }^{16}$

RICARDO coloca a sua teoria, basicamente, nos seguintes termos: "O lucro é o excedente, ou a diferença residual entre a quantidade de trabalho necessária à manutenção dos trabalhadores e o valor total da produção (estando o lucro, portanto, condicionado à produtividade do trabalho)" ${ }^{17}$ Ele distinguiu o valor de um bem determinado pela quantidade relativa de trabalho necessária à sua produção - do preço do trabalho.

Ao contrário de SMITH, RICARDO coloca como questão central da economia política a distribuição de renda e não o crescimento, concordando com aquele apenas no tocante à origem do valor e da riqueza, no trabalho. Ademais, afirma que somente o trabalho deve garantir o rendimento. ${ }^{18}$

Em que pese a importância dos referenciais teóricos acima mencionados, de outro lado, houve a ineficiência de uma construção teórica da economia política clássica, de dar respostas ao que realmente ocorria no plano concreto, traduzindo-se como o próprio fundamento da sua crise e superação, já que o otimismo com o progresso diante do capitalismo inviabilizou sua sustentação. ${ }^{19}$

Mais a frente, o século XIX faz da organização do trabalho o objeto de atenção de diversos reformadores sociais, dentre eles KARL MARX, cuja influência rompeu fronteiras. A contribuição marxista, mesmo compromissada em entender o capital, centra sua atenção no estatuto do trabalho sob o capital.

Referido cientista social estabeleceu uma profunda ruptura com os economistas clássicos por caminhar em uma trajetória própria, em que está devidamente

14 Cf. SMITH, Adam. A riqueza das nações: investigação sobre sua natureza e suas causas. São Paulo: Abril Cultural, 1983.

15 No primeiro momento em que o trabalho aparece na construção da economia ele se apresenta enquanto esforço, cansaço físico. Trata-se do primeiro esforço a ser pago. Ver SMITH, Adam. Op. cit., p. 63.

16 Cf. RICARDO, David. Princípios de economia política e tributação. São Paulo: Abril Cultural, 1982.

17 LIEDKE, Elida Rubini. Trabalho. In: CATTANI, Antonio David (org.). Trabalho e tecnologia: dicionário crítico. 2. ed. Petrópolis: Vozes, 1999, p. 270.

18 RICARDO, David. Op. cit., p.87. Essa forma ricardiana pode ser analisada como uma defesa da necessária submissão de todos à condição de trabalhadores, bem como o risco para a acumulação se tal não ocorresse.

19 Tal otimismo pode ser verificado a partir do manifesto de JACCARD: "o liberalismo econômico da época persuadiu-se de que o enriquecimento de alguns era a condição de felicidade de todos". (JACCARD, Pierre. Psicossociologia do trabalho. Lisboa: Moraes, 1969, p. 23) 
conscientizada a fratura histórica entre trabalho e força de trabalho. Segundo MARX, o trabalho é o centro da atividade humana enquanto luta para dominar a natureza, e é a partir dele que os homens produzem a si mesmos e aos outros e, portanto, relacionamse entre si.

O trabalho, então, é um verdadeiro exercício de liberdade, consubstanciado em uma forma plena e consciente. No entanto, à medida que a relação capitalista se aprofunda, e com isso a divisão social do trabalho se diferencia, o trabalho se transfigura de atividade consciente em atividade alienada, pois é só o mesmo que gera riqueza e justamente quem a produz não tem a ela direito. Ou seja, o homem aliena sua força de trabalho para gerar riqueza privada, de poucos. E nesse tipo de atividade ele se torna infeliz, não desenvolvendo sua potencialidade, sentindo-se fora de si mesmo e só se sentindo ele próprio, quando muito, fora do trabalho.

Assim, de atividade humana que objetiva dominar e transformar a natureza, o trabalho transforma-se em atividade "parcelizada", "rotinizada", submissa e rejeitada.

\section{O TRABALHO PULVERIZADO}

Evidenciou-se uma insuficiência de instrumental teórico disponível para o entendimento mais adequado do que ocorreu no mundo capitalista, no século XX, notadamente no período chamado fordista, o qual exigiu drásticas modificações nas relações entre capital e trabalho, em que a força de trabalho foi colocada de modo cada vez mais intenso sob uma forma de exploração e marginalização pelo capital.

As mudanças tecnológicas implementadas com informática e telecomunicações trouxeram profundas alterações na forma de conceber o trabalho, introduzindo inclusive novas modalidades de trabalho, o que induz a se pensar acerca do trabalho como não mais categoria central da sociedade, eis que a crise econômica, juntamente com os desequilíbrios sociais e políticos, favorecem ao alastramento da problemática que se instaura nas relações sociais.

Atualmente boa parte da atividade produtiva está mais relacionada à informação do que propriamente à transformação da matéria, pois se vive em uma transição da sociedade industrial para a chamada sociedade da informação, que se insere na nova ordem econômica, com a preponderância do trabalho intelectual sobre o manual.

Diante disso, há de fato uma dificuldade real enfrentada no trato analítico da categoria trabalho, sendo que tais problemas engendram uma perda da centralidade dessa categoria devido às diversas formas pelas quais o trabalho se manifesta, como o trabalho a tempo parcial, subemprego, informalidade etc., que coexistem neste estágio de desenvolvimento histórico.

A necessidade de desafiar a subordinação estrutural hierárquica do trabalho ao capital continua sendo a grande questão do nosso tempo. Por isso, o enfrentamento dessa questão é impensável sem a reafirmação vigorosa da centralidade do trabalho, o qual se fragmenta à medida que o capitalismo se torna mais desenvolvido, o que é merecedor de adequada reflexão que permita sua incorporação pelas distintas elaborações teóricas. 


\section{CONSIDERAÇÕES FINAIS}

A noção de trabalho humano associa-se, de um lado, a um significado degradante, expresso na Antigüidade, e de outro, penoso e gratificante, expresso pela interpretação humanista do trabalho. Nesse âmbito, com as Reformas Protestante e Católica, no século XVI, e a hegemonia do capitalismo, a partir do final do século XVIII, o trabalho fora incorporado à ideologia burguesa como categoria universal e fundadora de toda a vida social, como atividade natural de produção e troca de valores de uso, necessária à reprodução material da vida em sociedade. Vê-se que esta sociedade, ao longo da história, absorveu uma noção relativizada do trabalho, partindo do "comerás o pão com o suor do teu rosto" até o "time is money". 20

A partir da lição dos clássicos, verifica-se que novas dimensões e formas de relacionamento na sociedade pós-industrial procuram identificar no valor-conhecimento não mais no binômio valor-trabalho - novas características estruturais, traduzindo-se num perfil diferenciado das relações, baseado na colaboração entre fornecedores, porém, sempre na perspectiva da cooptação do trabalho pelo capital, ainda que o discurso seja outro.

Ou seja, as imensas possibilidades de um magnífico progresso de conhecimento, pelo trabalho humano, poderão se frustrar em uma tecnologia destrutiva da natureza e distanciada da felicidade dos homens. ${ }^{21}$ Porém, se a categoria "trabalho" for resgatada e alçada como o eixo condutor da sociedade, certamente o trabalho poderá desfrutar de vantagens advindas de uma nova ideologia de trabalho da sociedade do século XXI.

\section{REFERÊNCIAS BIBLIOGRÁFICAS}

ALBORNOZ, Suzana. O que é trabalho. São Paulo: Brasiliense, 2000.

CARMO, Paulo Sérgio do. A ideologia do trabalho. 8. ed. São Paulo: Moderna, 1996.

DE MASI, Domenico. Desenvolvimento sem trabalho. 4. ed. São Paulo: Esfera, 1999.

JACCARD, Pierre. Psicossociologia do trabalho. Lisboa: Moraes, 1969.

LIEDKE, Elida Rubini. Trabalho. In: CATTANI, Antonio David (org.). Trabalho e tecnologia: dicionário crítico. 2. ed. Petrópolis: Vozes, 1999.

MENDES, Antonio Celso. Direito: ciência, ideologia, política. Curitiba: Livros HDV, 1984.

RICARDO, David. Princípios de economia política e tributação. São Paulo: Abril, 1982.

SMITH, Adam. A riqueza das nações: investigação sobre sua natureza e suas causas. São Paulo: Abril Cultural, 1983.

THOMPSON, Edward P. A formação da classe operária inglesa: a maldição de Adão. Rio de Janeiro: Paz e Terra, v. 2, 1987.

WEBER, Max. A ética protestante e o espirito do capitalismo. 15. ed. São Paulo: Pioneira, 2000.

20 Provérbio inglês, já prefigurado em uma frase de TEOFRASTO (372? - 287 a.C.).

21 É o que ERNEST BLOCH, conhecido por suas novas interpretações das utopias e da esperança dos homens, chama de moratória da técnica do capitalismo: quando a técnica, da qual a humanidade esperava a abundância e a felicidade, portanto, a paz, aplica-se especialmente à indústria da guerra $\mathrm{e}$ aos interesses supra-estatais. Ver ALBORNOZ, Suzana. Op. cit., p. 22-23. 